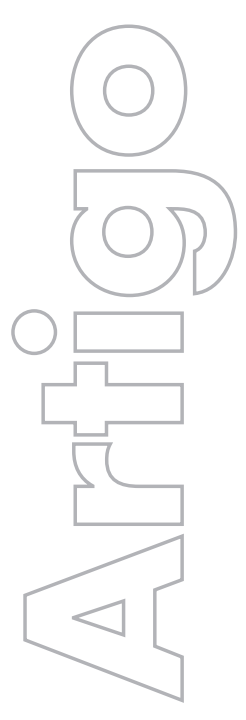

revista

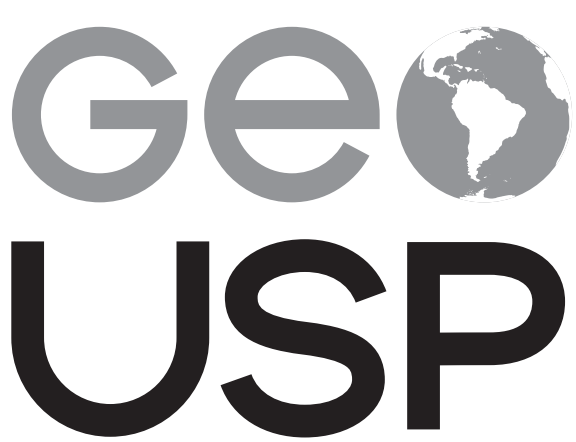

espaço e tempo

Volume $22 \cdot n^{\circ} 1(2018)$

ISSN 2179-0892
Análise sazonal e anual dos requisitos climáticos do cultivo da nogueira pecã (Carya illinoinensis) no Rio Grande do Sul

Franciele Francisca Marmentini Rovani UFSC

Cássio Arthur Wollmann

UFSM

p. $191-209$

Como citar este artigo:

ROVANI, F. F. M.; WOLLMANN, C. A. Análise sazonal e anual dos requisitos climáticos do cultivo da nogueira pecã (Carya illinoinensis) no Rio Grande do Sul. Geousp Espaço e Tempo (Online), v. 22, n. 1, p. 191-209, mês. 2018. ISSN 2179-0892.

Disponível em: <http://www.revistas.usp.br/geousp/article/ view/122043>. doi: http://dx.doi.org/10.11606/issn.21790892.geousp.2018.122043.

\section{(C) $(1)(9$}

Este artigo está licenciado sob a Creative Commons Attribution 4.0 License. 


\title{
Análise sazonal e anual dos requisitos climáticos do cultivo da nogueira pecã (Carya illinoinensis) no Rio Grande do Sul ${ }^{1}$
}

\section{Resumo}

Este estudo analisa os principais requisitos climáticos do cultivo da nogueira pecã no Rio Grande do Sul. Coletaram-se dados diários de temperatura média do ar, umidade relativa do ar e precipitação pluviométrica entre 1998 e 2013, junto às 23 estações meteorológicas do Inmet. O mapa de horas de frio foi elaborado com base nas informações de Herter et al. (2002). Fizeram-se análises estatísticas, e se espacializaram os dados sazonais e anuais por meio de krigagem e análise de regressão linear múltipla. Como resultado, destaca-se que, exceto pelo número de horas de frio, os demais requisitos são atendidos em todo o estado. Assim, devido às condições favoráveis, o cultivo de nogueira pecã apresenta potencial de desenvolvimento no Rio Grande do Sul.

Palavras-chave: Climatologia. Horas de frio. Temperatura do ar. Krigagem. Nogueira pecã.

\section{Seasonal and annual analysis of climatic requirements for cultivation of pecan (Carya illinoinensis) in Rio Grande do Sul}

\begin{abstract}
This research analyzed the main climatic requirements for the development for cultivation of pecan in Rio Grande do Sul. Were collected daily data of average air temperature, relative humidity and rainfall, from 1998 to 2013, of 23 weather stations of Inmet. The chilling hours map was elaborated with information from Herter et al. (2002). Statistical analyzes were performed and seasonal and annual data were spatialized through kriging and multiple linear regression analysis. As a result, it is emphasized that, except for the number of chilling hours, the other requirements are attend throughout the state. Pecan cultivation has a significant potential to growth in Rio Grande do Sul due to favorable weather conditions.
\end{abstract}

Keywords: Climatology. Chilling hours. Air temperature. Kriging. Pecan.

\footnotetext{
Agradecemos à Fundação de Amparo a Pesquisa do Rio Grande do Sul (Fapergs) e à Coordenação de Aperfeiçoamento de Pessoal de Ensino Superior (Capes) pela concessão da bolsa de doutorado, e ao Conselho Nacional Científico e Tecnológico (CNPq) pela concessão da bolsa de doutorado sanduíche, ambas da primeira autora.
} 


\section{Introdução}

Cultivo da nogueira pecã (Carya illinoinensis) foi introduzido no Brasil por imigrantes estadunidenses em meados de 1910, estabelecendo-se em algumas regiões do estado de São Paulo como Americana, Santa Bárbara e Piracicaba (Mota; Zahler, 1994; Lacerda; Lorenzi, 2006). A nogueira pecã é originária do sudoeste dos EUA e do norte do México e ocorre naturalmente nos vales dos rios Mississipi, Ohio, Missouri, Colorado e Guadalupe (Madero, 2003).

Atualmente, o cultivo merece destaque no Brasil, pois houve um incremento significativo da área plantada e, consequentemente, da produtividade das nozes. Na região Sul, o cultivo da nogueira pecã se destaca; estima-se que haja em torno de 10.000 hectares plantados (Fronza; Hamann, 2016). No Rio Grande do Sul, segundo dados da Emater-RS/Ascar (2014), existem mais de 3.396 hectares plantados, com produção superior a 1.695 toneladas de nozes.

Seu potencial de expansão é considerável, evidenciando-se um mercado promissor, devido ao crescimento do consumo diário de nozes, estimulado pelos benefícios à saúde (Duarte; Ortiz, 2001) e aliado ao alto valor comercial. Além disso, a noz pecã constitui-se em uma boa alternativa de produção em médio e em longo prazo, que não requer grandes investimentos e apresenta grandes possibilidades de exportação (Cabo, 2006).

Nesse contexto, é fundamental conhecer os requisitos climáticos necessárias ao desenvolvimento do cultivo, bem como suas adaptações às regiões onde foi introduzido. De acordo com Mota e Zahler (1994), a nogueira pecã se desenvolve bem em clima temperado ou subtropical, com temperaturas baixas durante o inverno, para o repouso vegetativo, e altas temperaturas no verão, favorecendo o florescimento e a frutificação. Assim, as principais exigências climáticas para o cultivo são a temperatura do ar, a umidade relativa do ar, a precipitação pluviométrica e o número de horas de frio.

Para Grageda et al. (2013), a temperatura afeta o desenvolvimento dos cultivos, insetos e patógenos, pois influi nos processos metabólicos. As médias mensais favoráveis ao desenvolvimento da nogueira pecã devem situar-se entre $24^{\circ} \mathrm{C}$ a $30^{\circ} \mathrm{C}$, durante o período de crescimento, com pequena variação entre temperaturas diurnas e noturnas (Raseira, 1990).

Quanto à umidade, estudos relatam que, quando elevada em determinadas fases fenológicas, afeta consideravelmente a cultura, por ensejar o desenvolvimento de patógenos. De acordo com Heerema, Goldberg e Thomas (2010), a sarna, causada pelo fungo Cladosporium caryigenum, é a doença mais comum e prejudicial à nogueira, favorecida por chuvas frequentes, alta umidade e temperaturas acima de $21^{\circ} \mathrm{C}$. Compromete tecidos jovens em crescimento (folhas, pecíolos, epicarpo dos frutos e amentos), podendo causar prejuízos de 50 a 100\% em períodos de muita umidade (Fronza; Poletto; Hamann, 2013). Além disso, a umidade influencia o deslocamento do pólen. Segundo Brison (1976), quando a umidade relativa durante o período de polinização é superior a $80 \%$, limita-se a polinização efetiva devido ao fato de as flores masculinas não conseguirem se abrir para liberar o pólen.

A nogueira pecã é uma árvore que requer disponibilidade de água acima de 800 mm anuais. Autores como Sparks (2005) indicam que as precipitações médias devem ser em torno de 1.000 mm a 1.300 mm e outros, tais como Peterson (1990), Sierra, López e Pérez (2007) sugerem precipitação anual mínima de 750 mm e máxima de $2.000 \mathrm{~mm}$. A falta de água pode ser resolvida por sistemas de irrigação, mas o efeito da umidade excessiva no solo só pode ser minimizado em locais de drenagem adequada, ou seja, em encostas mais do que em áreas planas (Sparks, 2005). 
Esse cultivo é bastante tolerante ao frio devido à grande variação de temperatura nas áreas em que é nativa (Sparks, 1995, 2005). Por ser uma planta caducifólia e de clima temperado, necessita de um período com temperaturas abaixo de $7^{\circ} \mathrm{C}$ no inverno, para entrar em repouso vegetativo e depois brotar e frutificar satisfatoriamente (Feio, 1991). Em regiões deficientes de frio, onde não se satisfazem as necessidades de frio invernal, os pomares de nozes apresentam brotação deficiente, floração irregular num amplo período, folhagem raquítica e poucas ramificações, e o rendimento tendem a ser muito inferior a seu potencial (Ávila, 2006; Grageda et al., 2013).

Assim, como os demais cultivos agrícolas, a nogueira pecã tem requisitos climáticos específicos para cada fase fenológica. Apesar disso, as variedades de nogueira pecã têm mecanismos de adaptação às condições edafoclimáticas em que são cultivadas, e o principal objetivo deste estudo é identificar e analisar a temperatura média do ar, a umidade relativa do ar, a precipitação pluviométrica e o número de horas de frio necessárias ao cultivo da nogueira pecã no Rio Grande do Sul em períodos sazonais e anuais.

\section{Material e métodos}

Área de estudo

Por seu histórico de ocupação, e Rio Grande do Sul apresenta distintas características econômicas e culturais, influenciado também pela diversidade natural de seu território (Figura 1). $\bigcirc$ estado tem uma área territorial de $281.731,44 \mathrm{~km}^{2}$, ou $3,3 \%$ da área total nacional, e 497 municípios, com um total de 10.693.929 habitantes (IBGE, 2010), ou 5,6\% da população brasileira.

\section{Figura 1 - Localização da área de estudo}

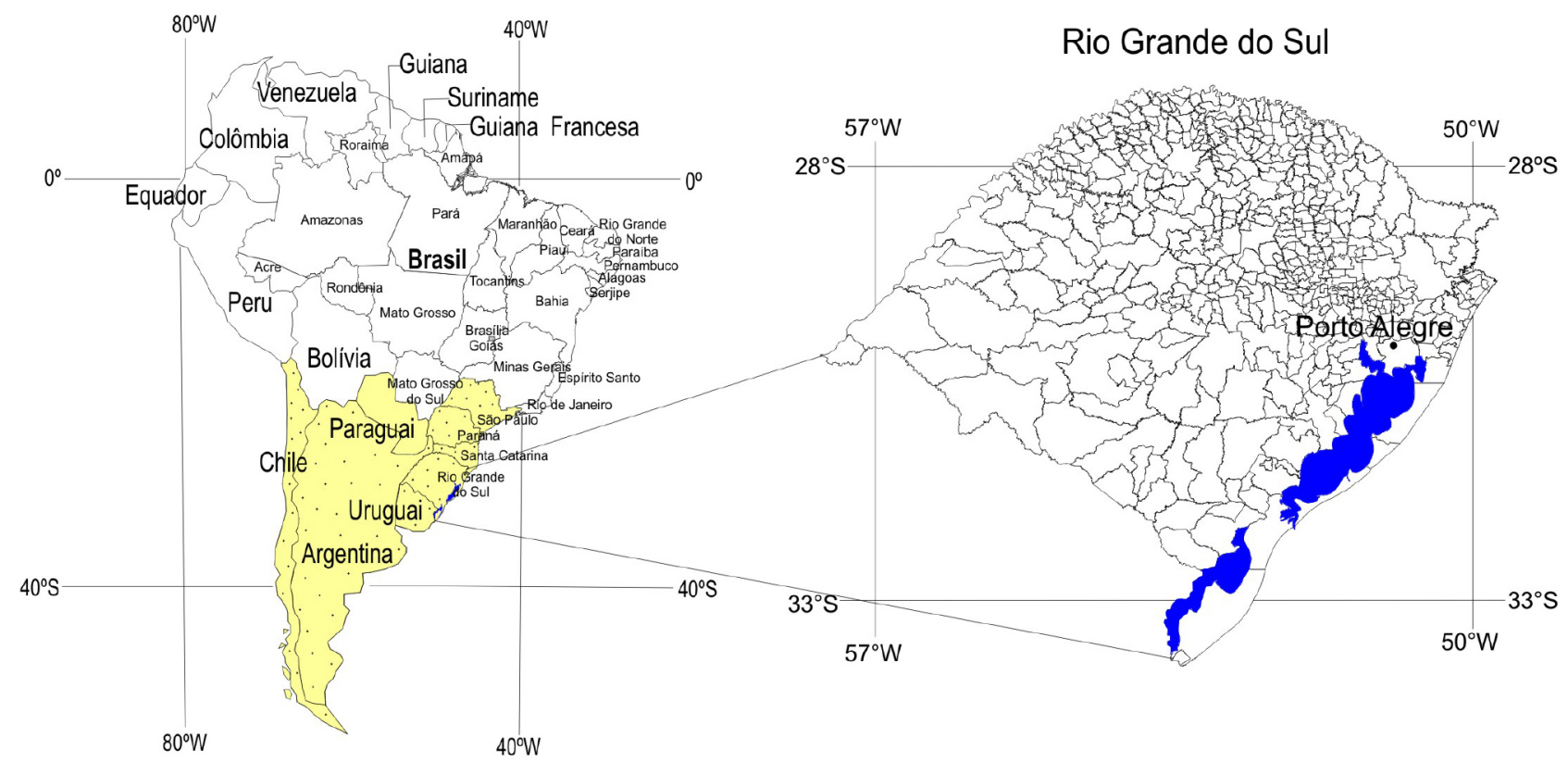


Quanto ao clima, de acordo com a tipologia definida e identificada por Rossato (2011), o Rio Grande do Sul tem quatro tipos de clima: (1) subtropical I, pouco úmido, que compreende as classes subtropical la, pouco úmido com inverno frio e verão fresco, e subtropical IB, pouco úmido com inverno frio e verão quente; (2) subtropical II, medianamente úmido, com variação longitudinal das temperaturas médias; (3) subtropical III, úmido, com variação longitudinal das temperaturas médias; e (4) subtropical IV, compreende as classes de subtropical IVa, muito úmido, com inverno fresco e verão muito quente, e subtropical IVb, muito úmido, com inverno frio e verão fresco.

\section{Coleta e organização dos dados}

Para o desenvolvimento deste estudo, coletaram-se os dados climáticos, em escala diária, das variáveis temperatura média do ar, precipitação pluviométrica e umidade relativa do ar. Esses foram obtidos num recorte temporal de 15 anos, de 1998 a 2013 exceto 2001, junto às 23 estações convencionais da rede do Instituto Nacional de Meteorologia (Inmet) do estado (Figura 2).

\section{Figura 2 - Localização das estações meteorológicas no Rio Grande do Sul}

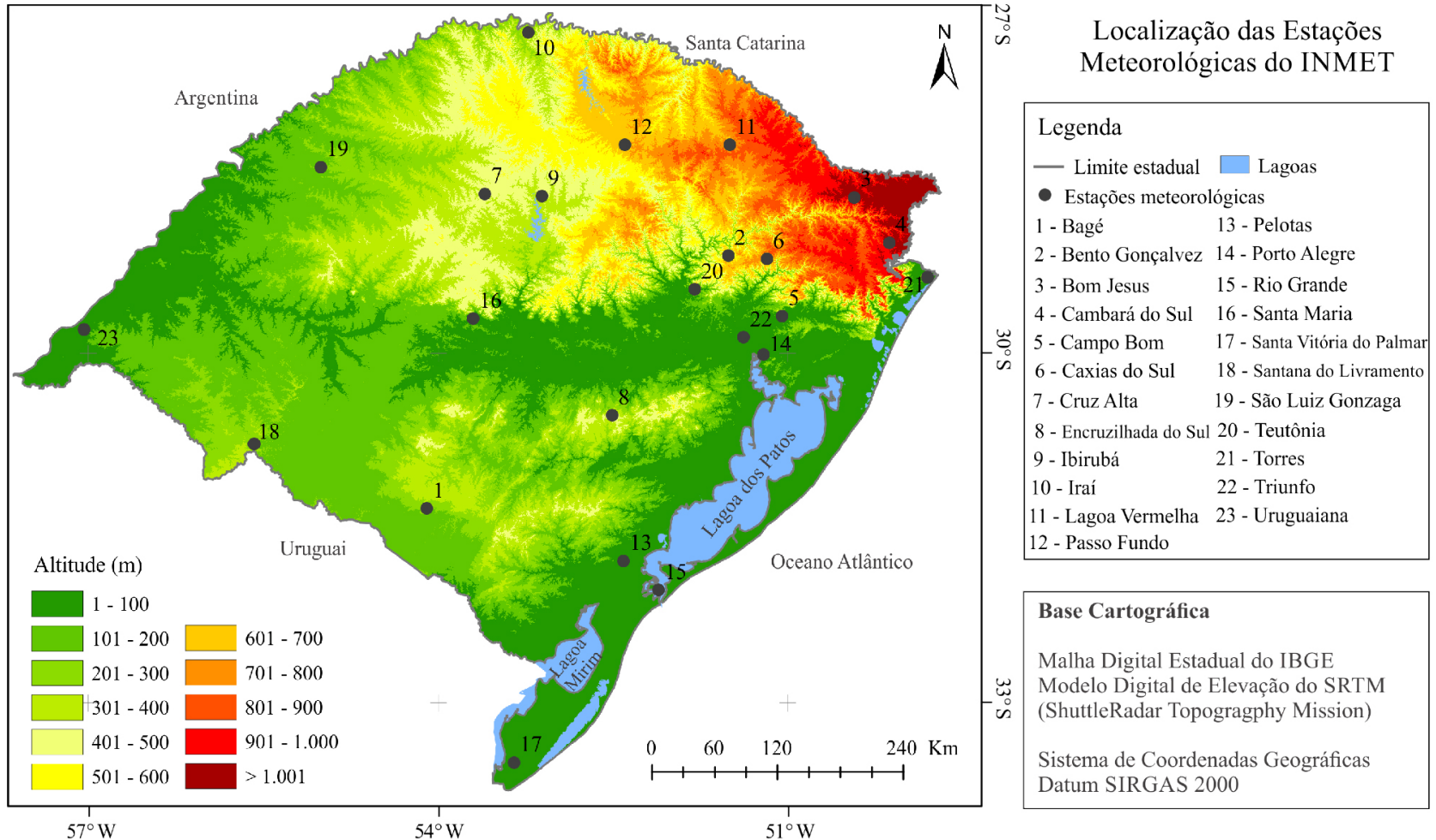

Os dados foram organizados em planilhas do Microsoft Office Excel por variável climática diária no período histórico das 23 estações meteorológicas. Nessa organização, procurou-se verificar sua constância na série histórica de acordo com o tempo (cronológico) e o espaço geográfico com base apenas na planilha dinâmica. Para a análise mensal e anual das variáveis temperatura e umidade relativa do ar, adotou-se o critério 3:5 da Organização Meteorológica 
Mundial (OMM, 1989), descartando-se as séries mensais com dados faltantes em três dias consecutivos ou cinco alternados. Para a precipitação pluviométrica, consideraram-se os dados mensais com no máximo três dias faltantes.

Também se utilizaram os dados relativos às horas de frio, definidas como temperaturas iguais ou abaixo de $7,2^{\circ} \mathrm{C}$, provenientes de um mapa pré-existente elaborado por Herter et al. (2002). De acordo com os autores, o mapa foi elaborado com dados climáticos de uma série histórica de 30 anos na qual se calculou o número de horas de frio de maio a setembro. $\bigcirc$ mapa original foi inserido no banco de dados geográficos, georreferenciado e digitalizado.

De posse dos dados organizados mensal, sazonal e anualmente, fizeram-se as análises estatísticas de tendência central, média aritmética e mediana e medidas de variabilidade como o desvio-padrão e os percentis (P05, P10, P90 e P95). Estes representam a porcentagem de valores que estão antes ou depois de determinado dado. Mostram as excepcionalidades individuais do conjunto de dados, permitindo compreender sua dinâmica no tempo e no espaço. Além disso, permitem entender a importância da latitude, do afastamento e da proximidade do mar, da altitude, da exposição à radiação solar e dos fluxos de ar predominantes em cada posto meteorológico (Monteiro et al., 2012).

Banco de dados e espacialização das variáveis

O banco de dados geográfico foi elaborado com o auxílio do software ArcGis versão 10.2.2 com o qual foi possível o gerenciamento e execução de operações de consulta, atualização, visualização e análise das informações. A base cartográfica da área de estudo foi elaborada com apoio da malha digital em formato vetorial do Rio Grande do Sul obtida junto ao IBGE (2015) e da imagem SRTM (Shuttle Radar Topography Mission), em forma de mosaico para todo o estado, organizada por Weber, Hasenack e Ferreira (2000).

Os dados de temperatura média do ar, precipitação pluviométrica e umidade relativa do ar, sazonal e anual, foram armazenados em tabelas de atributos do SIG. Para espacializar as variáveis precipitação e umidade relativa do ar, usou-se o interpolador krigagem, que apresentou resultados melhores que os interpoladores inverso do quadrado da distância e spline. Os dados referentes à variável temperatura foram representados pela análise de regressão linear múltipla, mas sem teste de normalidade dos dados. Essa análise relacionou a variável temperatura (dependente) com os dados de latitude, longitude e altitude (variáveis independentes). Para cada espacialização, foi preciso definir os dados de regressão, isto é, $\beta_{0}$ (constante de regressão), e os coeficientes de regressão $\beta_{1}$ (latitude), $\beta_{2}$ (longitude) e $\beta_{3}$ (altitude), juntamente com as imagens referentes a latitude e a longitude e o modelo numérico do terreno (Figura 3).

\section{Figura 3 - Equação representativa das constantes obtidas na regressão linear múltipla relativa à variável temperatura média do ar}

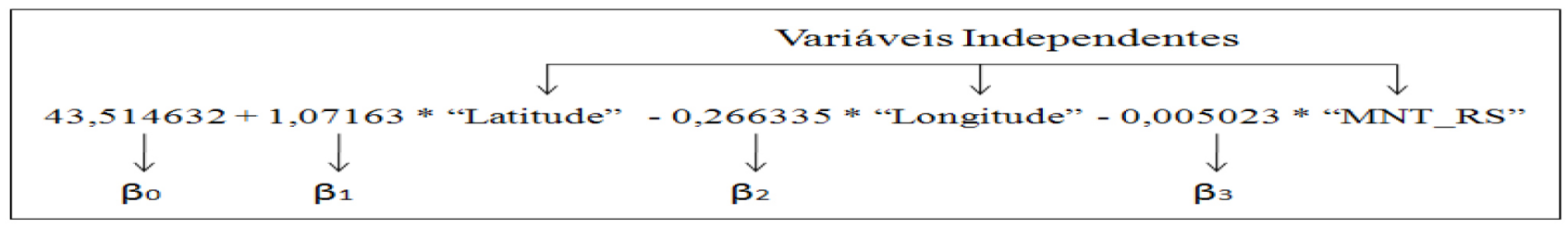


Por último, definiram-se as variáveis visuais a ser utilizadas nas representações, as classes e seus intervalos. Para a temperatura, definiu-se de $1{ }^{\circ} \mathrm{C}$ o intervalo dos dados a ser apresentados, variando de cores frias (tons de azul a verde) para as menores temperaturas a cores quentes (tons de laranja a vermelho) para as maiores. Para a precipitação, o intervalo de classes foi definido em $50 \mathrm{~mm}$ para a representação sazonal e em $100 \mathrm{~mm}$ para a anual, e a representação usa de uma escala que variou de tons de amarelo (menores precipitações) a tons de azul escuro (maiores precipitações). Para a umidade relativa do ar, o intervalo de classes consistiu de valores de $2 \%$, representadas com tons de azul mais claro para mais escuro (valores menores para maiores).

\section{Resultados e discussão}

A temperatura do ar sofre influência de fatores geográficos como latitude, altitude e continentalidade. De acordo com Sartori (2003), no Rio Grande do Sul, a latitude determina o ritmo das estações do ano e das temperaturas médias mensais e anuais, que acompanham as mudanças na insolação e na entrada de radiação solar entre os solstícios de inverno e verão e nos equinócios de primavera e outono. Para a autora, as temperaturas mais baixas são sempre registradas no topo do Planalto, e as mais altas, na Depressão Central ou no Vale do Uruguai. A temperatura média do ar no Rio Grande do Sul foi de $18,2{ }^{\circ} \mathrm{C}$ no período histórico, e sua representação sazonal e anual pode ser observada na Figura 4.

Verifica-se que a temperatura média anual variou de $14^{\circ} \mathrm{C}$ a $21^{\circ} \mathrm{C}$ (Figura 4). A fronteira noroeste, no Vale do Uruguai, e as regiões que compreendem São Luiz Gonzaga e Uruguaiana são as áreas com as temperaturas mais elevadas, coincidindo com as áreas de menores altitudes. No outro extremo, na região de Bom Jesus, onde as altitudes são mais elevadas, têm-se as menores temperaturas médias. A região central do estado, no limite entre o Rebordo do Planalto e a Depressão Periférica, verifica-se uma faixa de temperaturas entre $19^{\circ} \mathrm{C}$ e $20^{\circ} \mathrm{C}$.

Esses valores de temperatura média, registrados com base na série histórica de 15 anos, vêm ao encontro do que Sartori (2003) destaca em seu estudo da dinâmica do clima do Rio Grande do Sul, a partir das normais climatológicas do Inmet (1961-1990) e de outros estudos (Sartori, 1993, 2000). Em suas considerações a respeito dos atributos climáticos básicos, enfatiza que as temperaturas médias anuais variam entre $14^{\circ} \mathrm{C}$ e $18^{\circ} \mathrm{C}$ no topo do Planalto e Serra do Sudeste e entre $18^{\circ} \mathrm{C}$ e $20^{\circ} \mathrm{C}$ na Depressão Central, Campanha, Vale do Uruguai e Planície Litorânea.

As temperaturas sazonais apresentaram um padrão de espacialização muito similar ao que foi verificado na média anual. Na primavera e no outono, as temperaturas médias são muito semelhantes. A diferença é que, na primavera, as amplitudes médias variaram mais, de $13^{\circ} \mathrm{C}$ a $22^{\circ} \mathrm{C}$, ao passo que, no outono, variaram de $14^{\circ} \mathrm{C}$ a $21^{\circ} \mathrm{C}$. As menores temperaturas foram encontradas na região serrana, que compreende Bom Jesus e Cambará do Sul, e as maiores, na região da fronteira noroeste e na região central do estado.

No verão, a temperatura média situou-se entre os $17^{\circ} \mathrm{C}$ e os $27^{\circ} \mathrm{C}$, com uma amplitude térmica de $10{ }^{\circ} \mathrm{C}$, e predominaram as temperaturas superiores a $22^{\circ} \mathrm{C}$. No inverno, a temperatura média situou-se entre $10^{\circ} \mathrm{C}$ e os $16^{\circ} \mathrm{C}$. Prevaleceram as temperaturas abaixo dos $14^{\circ} \mathrm{C}$ na metade sul e no nordeste, incluindo as regiões de Cruz Alta, Ibirubá, Passo Fundo e 
Lagoa Vermelha. Novamente, esses dados corroboram a afirmação de Sartori (2003) de que, no inverno, a temperatura média do mês mais frio (julho) fica entre $10^{\circ} \mathrm{C} \mathrm{e} 15^{\circ} \mathrm{C}$ e, no verão, a do mês mais quente (janeiro) é superior a $22^{\circ} \mathrm{C}$ na maior parte do estado.

\section{Figura 4 - Temperatura média do ar sazonal e anual no Rio Grande do Sul}
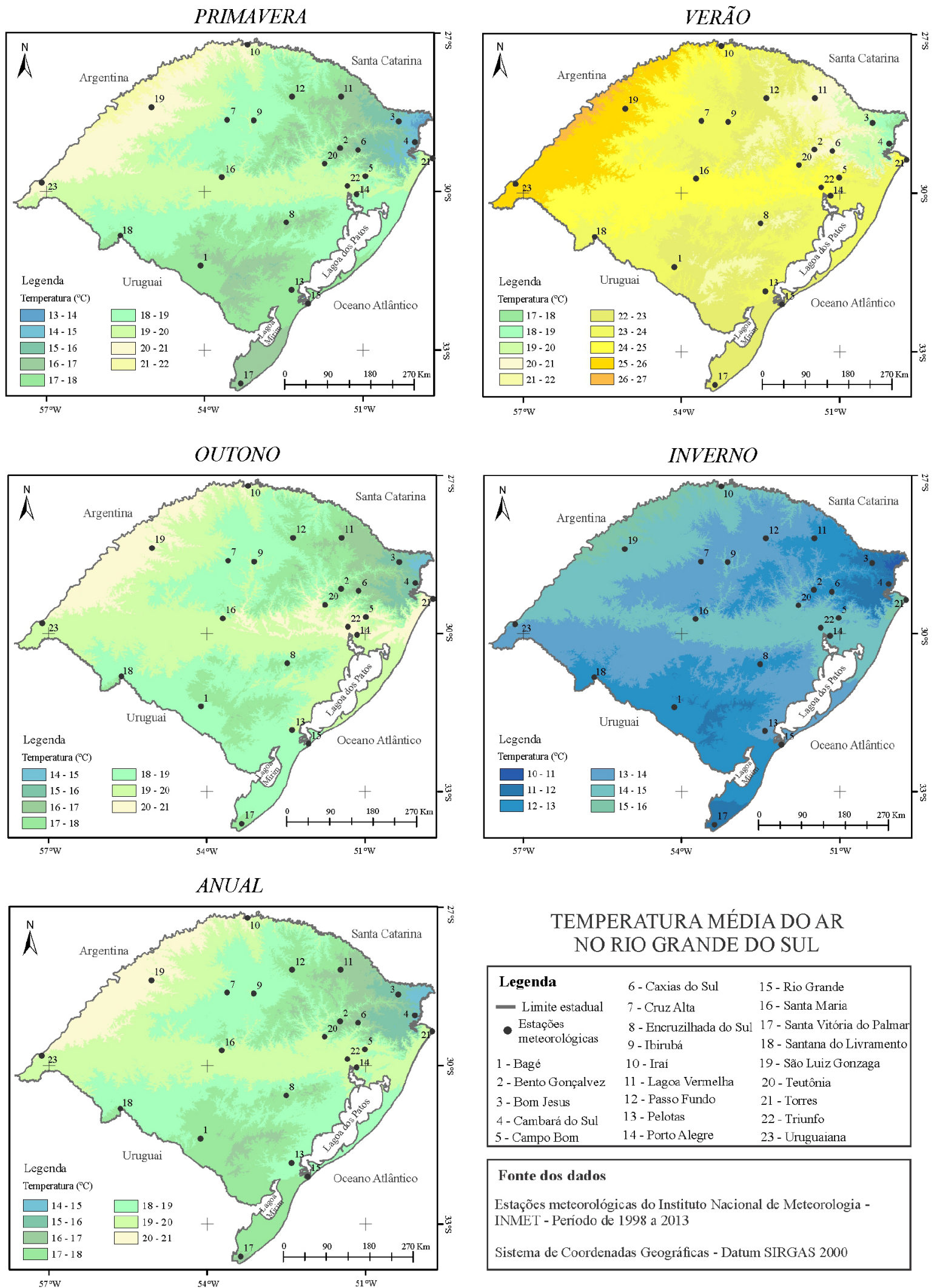

\section{TEMPERATURA MÉDIA DO AR} NO RIO GRANDE DO SUL

\begin{tabular}{|c|c|c|}
\hline Legenda & 6 -Caxias do Sul & 15 - Rio Grande \\
\hline - Limite estadual & 7 - Cruz Alta & 16 - Santa Maria \\
\hline $\begin{array}{l}\text { Estąões } \\
\text { meteorológicas }\end{array}$ & $\begin{array}{l}8 \text { - Encruzilhada do Sul } \\
9 \text { - Ibirubá }\end{array}$ & $\begin{array}{l}17 \text { - Santa Vitória do Palmar } \\
18 \text { - Santana do Livramento }\end{array}$ \\
\hline 1 - Bagé & $10-$ Traí & 19 - São Luiz Gonzaga \\
\hline 2 - Bento Gonçalvez & 11 - Lagoa Vermelha & 20 - Teutônia \\
\hline 3 - Bom Jesus & 12 - Passo Fundo & 21 - Torres \\
\hline 4 - Cambará do Sul & 13 - Pelotas & 22 - Triunfo \\
\hline 5 - Campo Bom & 14 - Porto Alegre & 23 - Uruguaiana \\
\hline
\end{tabular}

Fonte dos dados

Estações meteorológicas do Instituto Nacional de Meteorologia INMET - Período de 1998 a 2013

Sistema de Coordenadas Geográficas - Datum SIRGAS 2000 
Como destaca Sparks (1996, 2005), a nogueira pecã requer temperaturas médias anuais em torno de $18,3^{\circ} \mathrm{C}$, média muito similar a do estado $\left(18,2^{\circ} \mathrm{C}\right)$. De acordo com Raseira (1990), no período de crescimento das nozes, de outubro a abril, a temperatura média deve estar entre $24^{\circ} \mathrm{C}$ e $30^{\circ} \mathrm{C}$, requisito verificado no estado, especialmente na região noroeste. Segundo Manaster (1994), no verão, nos meses de dezembro, janeiro e fevereiro, os nogais preferem temperaturas médias relativamente altas, superiores a $23,9^{\circ} \mathrm{C}$, requisito atendido em praticamente toda a área de estudo durante o verão. A média histórica anual da temperatura pode ser vista na Tabela 1.

\section{Tabela 1 - Temperatura média do ar: média histórica anual, mediana, desvio padrão $(S)$ e percentis P5, P10, P90 e P95 no Rio Grande do Sul - 1998-2013}

\begin{tabular}{|l|l|l|l|l|l|l|l|}
\hline \multicolumn{2}{|c|}{ temperatura média do ar $\left({ }^{\circ} \mathrm{C}\right)$} \\
\hline ano & média & mediana & $\begin{array}{c}\text { S } \\
\left({ }^{\circ} \mathrm{C}\right)\end{array}$ & P5 & P10 & P90 & P95 \\
\hline 1998 & 18,0 & 17,9 & 1,6 & 14,8 & 15,9 & 19,7 & 20,1 \\
\hline 1999 & 18,1 & 18,3 & 1,7 & 15,5 & 16,5 & 19,9 & 20,2 \\
\hline 2000 & 17,9 & 18,0 & 1,6 & 14,5 & 16,3 & 19,3 & 20,0 \\
\hline 2002 & 18,6 & 18,6 & 1,5 & 16,6 & 17,2 & 20,6 & 20,9 \\
\hline 2003 & 18,2 & 18,3 & 1,5 & 15,2 & 16,7 & 19,7 & 20,2 \\
\hline 2004 & 18,2 & 18,4 & 1,6 & 14,9 & 16,8 & 19,6 & 20,2 \\
\hline 2005 & 18,6 & 18,8 & 1,6 & 15,2 & 17,1 & 20,1 & 20,8 \\
\hline 2006 & 18,5 & 18,4 & 1,6 & 15,3 & 17,0 & 20,1 & 20,7 \\
\hline 2007 & 18,2 & 18,3 & 1,5 & 15,2 & 16,7 & 19,8 & 20,4 \\
\hline 2008 & 17,9 & 18,0 & 1,7 & 14,5 & 16,5 & 19,5 & 20,2 \\
\hline 2009 & 18,1 & 18,1 & 1,5 & 15,1 & 16,8 & 19,6 & 20,3 \\
\hline 2010 & 18,1 & 18,5 & 1,6 & 15,0 & 16,3 & 19,8 & 20,0 \\
\hline 2011 & 18,0 & 17,8 & 1,5 & 16,2 & 16,5 & 19,8 & 20,2 \\
\hline 2012 & 18,9 & 18,5 & 1,5 & 17,2 & 17,5 & 20,8 & 21,1 \\
\hline 2013 & 18,0 & 17,8 & 1,5 & 16,0 & 16,5 & 19,7 & 20,0 \\
\hline
\end{tabular}


$\bigcirc$ ano que apresentou a maior temperatura média histórica foi 2012, registrando $18,9^{\circ} \mathrm{C}$ e, os de menor média foram 2000 e 2008 , registrando $17,9^{\circ} \mathrm{C}$. Isso representa uma diferença na média de $1^{\circ} \mathrm{C}$, um número significativo. A mediana, valor que divide o conjunto em duas partes iguais, apresentou em 2002 e 2009 valor igual à média; em $2010,18,5^{\circ} \mathrm{C}$, isto é, $0,4^{\circ} \mathrm{C}$ a mais que a média; e, em $2012,18,5^{\circ} \mathrm{C}$, ou $0,4^{\circ} \mathrm{C}$ a menos que a média.

desvio-padrão apresentou variação de 1,5 a $1,7^{\circ} \mathrm{C}$ em relação à média, indicando pouca dispersão entre os dados. $\bigcirc$ menor valor do P5 foi de $14,5^{\circ} \mathrm{C}$, registrado em 2000 e 2008. O maior valor desse percentil foi de $17,2^{\circ} \mathrm{C}$, em 2012 . Isso representa uma variação de $2,7^{\circ} \mathrm{C}$ entre os $5 \%$ das menores temperaturas. No P95, destaca-se novamente o ano de 2012, com o maior valor, $21,1^{\circ} \mathrm{C}$. Os anos de 2000, 2010 e 2013 apresentaram o menor valor do P95, isto é, $20^{\circ} \mathrm{C}$. Isso mostra uma maior variação história entre as menores temperaturas (5\%) do que entre as maiores (95\%). Além disso, nota-se que 2012 é o ano com as temperaturas médias mais altas da série histórica.

A variação espacial da chuva no estado sofre, em parte, a influência do relevo, uma vez que tem a Serra Geral em seu setor central, com alinhamento perpendicular à direção geral do deslocamento das frentes polares, e, no litoral norte, alinhada no sentido N-S, cujos ventos de leste e nordeste podem produzir aumento das chuvas, como destaca Sartori (2003). Além disso, a autora enfatiza que a variabilidade têmporo-espacial das precipitações, resultando em episódios de longas estiagens ou enchentes, pode ocorrer em qualquer época do ano e remete às alterações na habitualidade da circulação atmosférica nas escalas regional e zonal, em parte provocadas pelos fenômenos El Niño e La Niña (Sartori, 1993, 2003). A precipitação pluviométrica média no Rio Grande do Sul é de 1.651 mm anuais, e a Figura 5 retrata sua representação sazonal e anual.

A precipitação pluviométrica média anual variou de $1.200 \mathrm{~mm}$ a $2.000 \mathrm{~mm}$. Os meses mais chuvosos, de acordo com a frequência, são setembro e outubro, na maior parte do estado, dado também comprovado por Sartori (2003), e o mês de maio é tido como o menos chuvoso. Os menores registros $(1.200 \mathrm{~mm}$ a $1.400 \mathrm{~mm})$ ocorreram nas regiões de Santa Vitória do Palmar e Rio Grande. Muito mais chuvosa, a porção norte do estado apresentou média pluviométrica entre $1.900 \mathrm{~mm}$ e $2.000 \mathrm{~mm}$, compreendendo as regiões de Iraí, Passo Fundo, São Luiz Gonzaga e Cruz Alta. A região central do estado, que abrange Santa Maria em direção a Bento Gonçalves, Lagoa Vermelha e Bom Jesus, apresentou média entre $1.700 \mathrm{~mm}$ e $1.800 \mathrm{~mm}$. Esses totais pluviométricos indicam satisfação hídrica anual da nogueira, pois Sparks (2005) indica que as precipitações médias devem ser em torno de $1.000 \mathrm{~mm}$ a $1.300 \mathrm{~mm}$, e outros autores como Peterson (1990) e Sierra, López e Pérez (2007) sugerem precipitação anual mínima de 750 mm e máxima de $2.000 \mathrm{~mm}$. 
Figura 5 - Precipitação pluviométrica sazonal e anual no Rio Grande do Sul
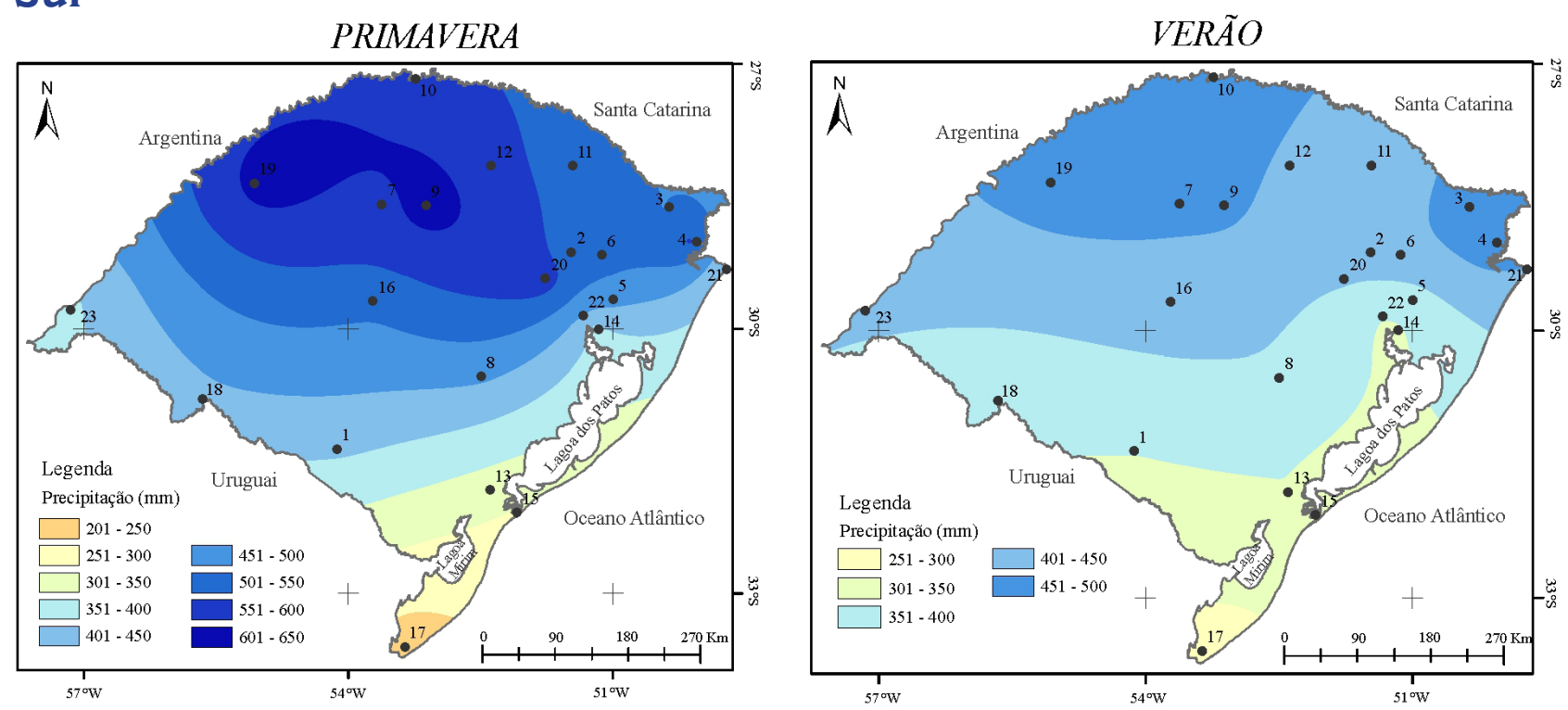

\section{OUTONO}
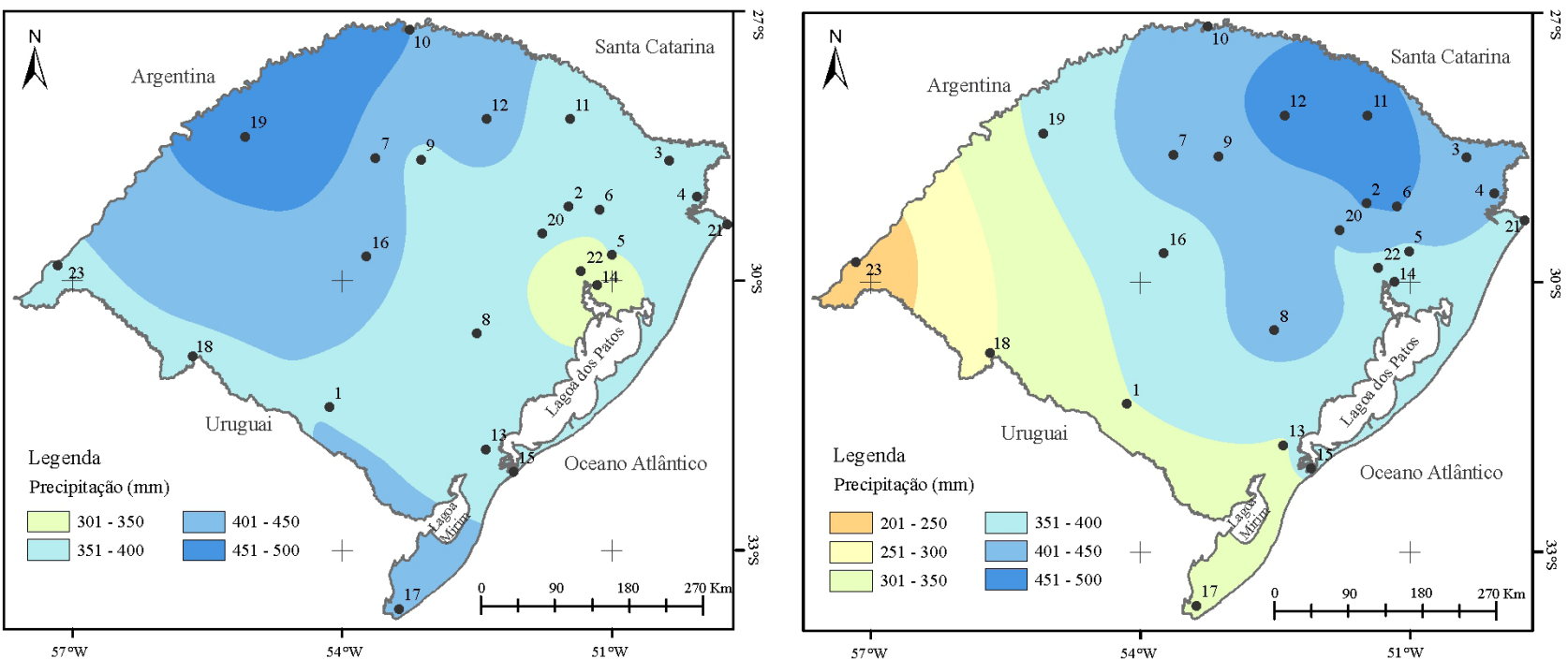

$A N U A L$

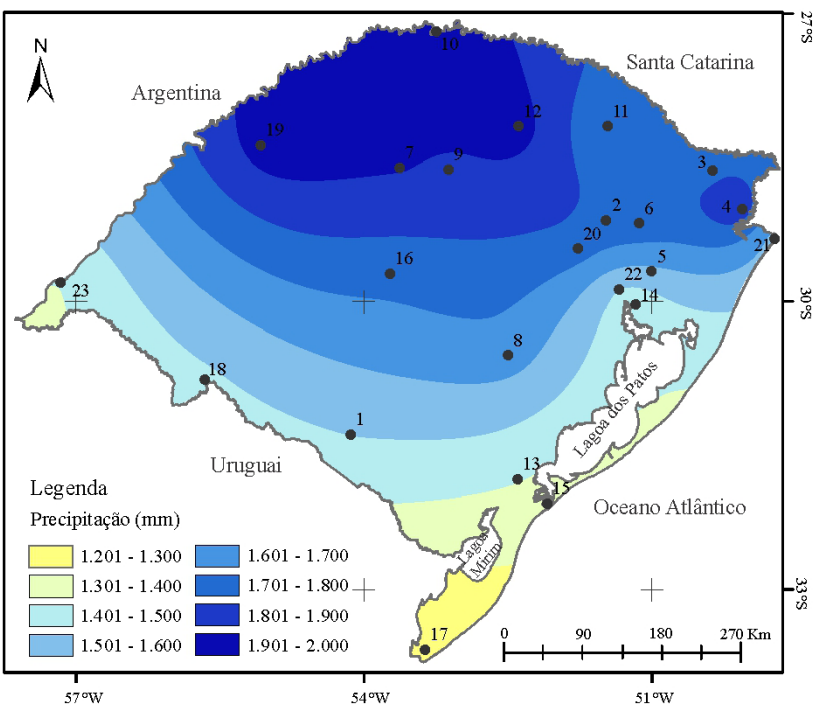

\section{PRECIPITAÇÃO PLUVIOMÉTRICA NO RIO GRANDE DO SUL}

\begin{tabular}{|lll|}
\hline Legenda & 6 - Caxias do Sul & 15 - Rio Grande \\
- Limite estadual & 7 - Cruz Alta & 16 - Santa Maria \\
- Estações & 8 - Encruzilhada do Sul 17 - Santa Vitória do Palmar \\
meteorológicas & 9 - Tbirubá & 18 - Santana do Livramento \\
1 - Bagé & 10 - Iraí & 19 - São Luiz Gonzaga \\
2 - Bento Gonçalvez & 11 - Lagoa Vermelha & 20 - Teutônia \\
3 - Bom Jesus & 12 - Passo Fundo & 21 - Torres \\
4- Cambará do Sul & 13 - Pelotas & 22- Triunfo \\
5 - Campo Bom & 14 - Porto Alegre & 23 - Uruguaiana \\
\hline
\end{tabular}

\section{Fonte dos dados}

Estações meteorológicas do Instituto Nacional de Meteorologia INMET - Período de 1998 a 2013

Sistema de Coordenadas Geográficas - Datum SIRGAS 2000 
Quanto ao regime pluviométrico sazonal, identifica-se uma diferença significativa entre as estações, porém sem secas sazonais definidas. A primavera apresenta maior variabilidade espacial da pluviosidade, entre $200 \mathrm{~mm}$ e $650 \mathrm{~mm}$, e uma distribuição espacial muito semelhante à representação anual. Trata-se de uma época transicional, com gradativo aquecimento continental e, por isso, a maior parte das chuvas resulta da atuação da Massa Polar Velha, seguida da Massa Polar Atlântica (Sartori, 2003). Diferentemente da primavera, o outono apresenta a menor variabilidade espacial da pluviosidade, ou seja, de 200 mm sazonais (301 mm-500 mm). As regiões de São Luiz Gonzaga e Iraí continuam apresentando os maiores valores, e as de Porto Alegre, Triunfo e Campo Bom, os menores.

No verão, a pluviosidade variou de $251 \mathrm{~mm}$ a $500 \mathrm{~mm}$, sendo o sul menos chuvoso que o norte do estado, com maior participação da Massa Polar Velha (MPV), seguida da Frente Polar Atlântica (FPA), como mostra Sartori (2003). Santa Vitória do Palmar registrou a menor média pluviométrica histórica para o mês de janeiro (53 mm), sendo esse mês um dos menos chuvosos da série histórica. No inverno, a variação da pluviosidade foi de $200 \mathrm{~mm}$ a $500 \mathrm{~mm}$. Observa-se que, na fronteira oeste, com a Argentina e com o Uruguai, até a região de Santa Vitória do Palmar, a pluviosidade registrada é de $201 \mathrm{~mm}$ a 350 mm, ou seja, os menores totais pluviométricos. Na região central, norte e leste, a precipitação variou de $351 \mathrm{~mm}$ a $500 \mathrm{~mm}$. No inverno, segundo Sartori (2003), destaca-se a presença da Massa Polar Atlântica (MPA), acentuando a sua atuação, devido ao resfriamento hibernal que atinge as latitudes médias e altas do Hemisfério Sul. Além disso, a diminuição geral das temperaturas e a intensificação das altas pressões de origem polar favorecem a permanência da MPA, durante até oito dias consecutivos.

A média histórica anual da precipitação permite verificar os anos de maior ou menor precipitação no estado e sua influência na produtividade das culturas (Tabela 2). Ao observar o total acumulado anual da série histórica, verifica-se que 2002 apresentou a maior média histórica $(2.200,9 \mathrm{~mm})$, seguido de 1998, com média de $1.959 \mathrm{~mm}$. Nos períodos de 1997-1998 e 2002-2003, destaca-se a ocorrência do fenômeno El Niño, de magnitudes forte e moderada (CPTEC, 2017), respectivamente, o que pode ter sido o fator mais influente no aumento significativo dos totais pluviométricos. $\bigcirc$ ano de 2004 apresentou a menor média histórica $(1.306,8 \mathrm{~mm})$ seguido de $2006(1.320,7 \mathrm{~mm})$ e 2012 (1.385,5 mm). $\bigcirc$ ano de 2011 apresentou precipitação mediana $(1.610,1 \mathrm{~mm})$, próximo à média $(1.612,8 \mathrm{~mm})$, e o de 2002 apresenta a maior variação entre a média e a mediana $(168,7 \mathrm{~mm})$. O desvio padrão mostra a variação dos dados em relação à média. $\bigcirc$ ano de 1998 foi o de maior variabilidade (469,1 mm), e o de 2004, o de menor (209,2 mm). 
Tabela 2 - Média histórica anual da precipitação, desvio-padrão (S), mediana e percentis P5, P10, P90 e P95 no Rio Grande do Sul - 1998-2013

\begin{tabular}{|l|l|l|l|l|l|l|l|}
\hline \multicolumn{2}{|l|}{ precipitação (mm) } \\
\hline ano & acumulado & mediana & $S(\mathrm{~mm})$ & P5 & P10 & P90 & P95 \\
\hline 1998 & $1.959,0$ & $1.919,5$ & 469,1 & $1.272,7$ & $1.406,6$ & $2.469,1$ & $2.698,3$ \\
\hline 1999 & $1.404,0$ & $1.378,2$ & 276,0 & $1.020,5$ & $1.065,2$ & $1.789,1$ & $1.840,7$ \\
\hline 2000 & $1.770,6$ & $1.730,9$ & 295,2 & $1.324,8$ & $1.491,3$ & $2.111,9$ & $2.227,6$ \\
\hline 2002 & $2.200,9$ & $2.032,2$ & 422,0 & $1.733,8$ & $1.810,3$ & $2.677,9$ & $2.846,8$ \\
\hline 2003 & $1.760,3$ & $1.746,1$ & 257,8 & $1.413,5$ & $1.440,9$ & $2.102,9$ & $2.139,0$ \\
\hline 2004 & $1.306,8$ & $1.296,9$ & 209,2 & $1.070,1$ & $1.070,1$ & $1.503,9$ & $1.532,9$ \\
\hline 2005 & $1.601,0$ & $1.524,1$ & 342,2 & $1.181,6$ & $1.202,9$ & $2.072,4$ & $2.086,5$ \\
\hline 2006 & $1.320,7$ & $1.296,1$ & 230,0 & $1.035,8$ & $1.085,2$ & $1.588,4$ & $1.638,3$ \\
\hline 2007 & $1.773,0$ & $1.754,5$ & 322,5 & $1.333,5$ & $1.410,4$ & $2.166,7$ & $2.215,5$ \\
\hline 2008 & $1.479,8$ & $1.500,6$ & 306,1 & $1.074,4$ & $1.109,2$ & $1.845,4$ & $1.932,7$ \\
\hline 2009 & $1.893,5$ & $1.959,6$ & 269,7 & $1.456,0$ & $1.656,0$ & $2.168,0$ & $2.194,4$ \\
\hline 2010 & $1.640,4$ & $1.679,9$ & 287,8 & $1.216,1$ & $1.310,2$ & $2.026,5$ & $2.034,9$ \\
\hline 2011 & $1.612,8$ & $1.610,1$ & 404,7 & $1.071,2$ & $1.113,9$ & $2.112,6$ & $2.153,4$ \\
\hline 2012 & $1.385,5$ & $1.404,7$ & 219,7 & 994,9 & $1.055,6$ & $1.616,8$ & $1.654,2$ \\
\hline 2013 & $1.656,8$ & $1.675,8$ & 277,7 & $1.249,3$ & $1.307,7$ & $1.973,0$ & $1.994,7$ \\
\hline
\end{tabular}

fonte: Inmet (2015).

Quanto aos percentis, notou-se que o P5 corresponde a 2012 (994,9 mm), enquanto o maior foi em $2002(1.733,8 \mathrm{~mm})$. No P95, verificou-se que o menor valor registrado foi em 2004 (1.532,9 mm) e o maior, em 2002 (2.846,8 mm). Destaca-se ainda que 2004 apresentou totais pluviométricos iguais em P5 e P10, apontando a menor variação entre os menores valores, apesar de as chuvas terem tido grande variação têmporo-espacial na área de estudo.

A média da umidade relativa do ar no Rio Grande do Sul é 77\%, e sua representação sazonal e anual podem ser observadas na Figura 6. A umidade relativa do ar anual variou de $73 \%$ a $84 \%$, com um descolamento no sentido noroeste-sudeste. Os menores valores foram registrados na região de Uruguaiana e São Luiz Gonzaga. A umidade superior a 81\% concentrou-se principalmente na faixa litorânea, que compreende as regiões de Pelotas, Rio Grande, Torres e Cambará do Sul. Na representação sazonal da umidade, também se constatam os maiores valores de umidade na porção litorânea, em função dos ventos úmidos que habitualmente sopram do mar.

Na primavera, a variação de umidade foi de 13\%, isto é, entre os valores de $71 \%$ e $84 \%$. As regiões de Cambará do Sul e Torres apresentaram umidade superior a 81\%. No outono, a umidade variou entre 75\% e 84\%, com aumento das áreas com valores superiores a 80\%. Para 
algumas variedades da nogueira pecã, mais propícias ao desenvolvimento da sarna, doença que afeta tanto as folhas como os frutos, a primavera merece atenção. A umidade superior a 80\% e mais de dois dias consecutivos são favoráveis ao desenvolvimento dessa doença.

\section{Figura 6 - Umidade relativa do ar sazonal e anual no Rio Grande do Sul}
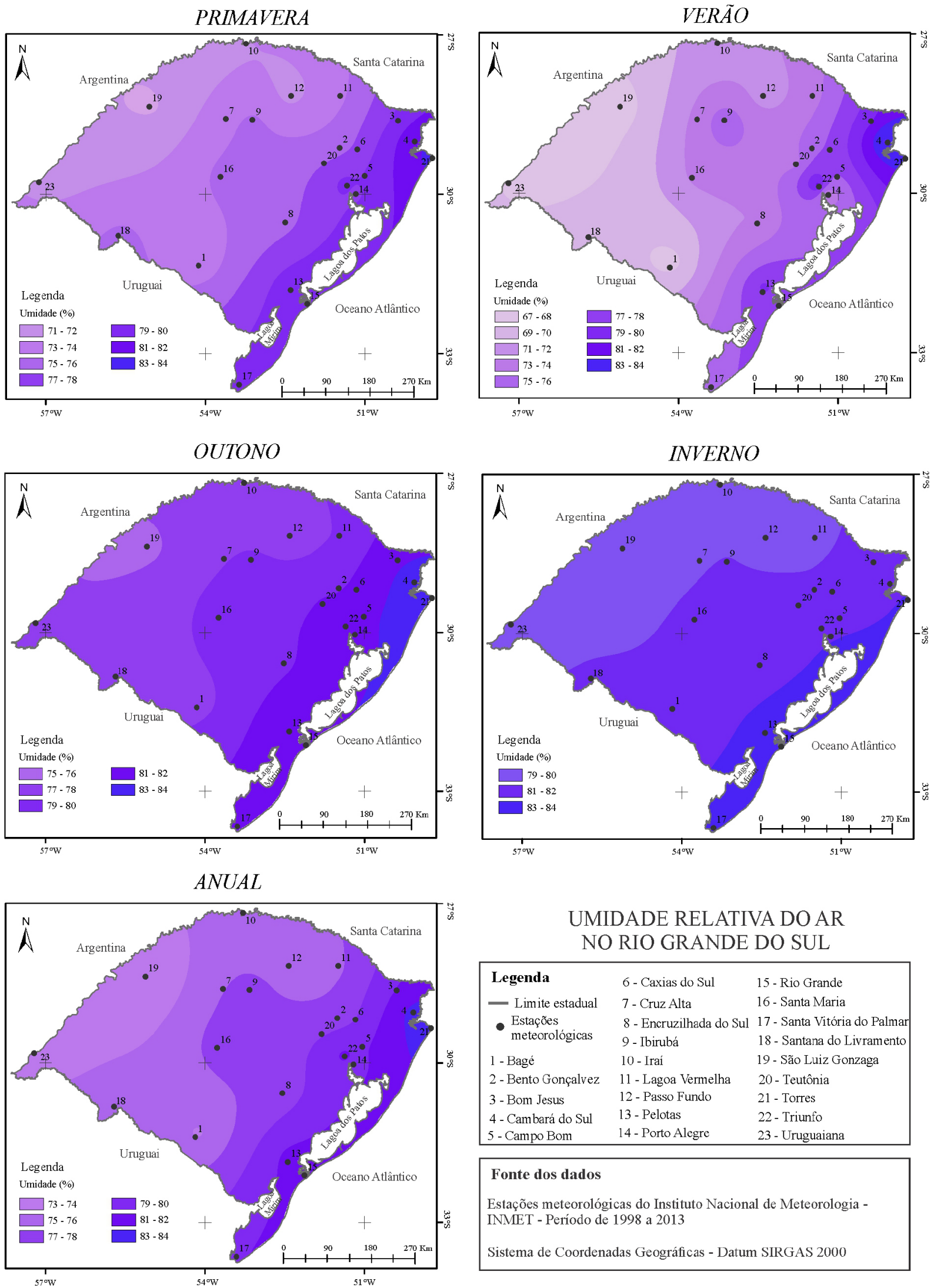

UMIDADE RELATIVA DO AR NO RIO GRANDE DO SUL

\begin{tabular}{|c|c|c|}
\hline Legenda & 6 - Caxias do Sul & 15 - Rio Grande \\
\hline - Limite estadual & 7 - Cruz Alta & 16 - Santa Maria \\
\hline $\begin{array}{l}\text { Estações } \\
\text { meteorológicas }\end{array}$ & $\begin{array}{l}8 \text { - Encruzilhada do Sul } \\
9 \text { - Ibirubá }\end{array}$ & $\begin{array}{l}17 \text { - Santa Vitória do Palmar } \\
18 \text { - Santana do Livramento }\end{array}$ \\
\hline 1 - Bagé & 10 - Iraí & 19 - São Luiz Gonzaga \\
\hline 2 - Bento Gonçalvez & 11 - Lagoa Vermelha & 20 - Teutônia \\
\hline 3 -Bom Jesus & 12 - Passo Fundo & 21 - Torres \\
\hline 4 - Cambará do Sul & 13 - Pelotas & 22 - Triunfo \\
\hline 5 - Campo Bom & 14 - Porto Alegre & 23 - Uruguaiana \\
\hline
\end{tabular}

\section{Fonte dos dados}

Estações meteorológicas do Instituto Nacional de Meteorologia INMET - Período de 1998 a 2013

Sistema de Coordenadas Geográficas - Datum SIRGAS 2000 
O verão apresentou a maior amplitude da umidade com $17 \%$ de variação entre o menor valor (67\%) e o maior valor (84\%) e os menores valores de umidade. As regiões que apresentaram umidade relativa até $70 \%$ compreendem praticamente toda a fronteira oeste do estado, com o Uruguai e a Argentina, abrangendo Santana do Livramento, Uruguaiana, São Luiz Gonzaga e Bagé. Os valores de umidade igual ou superiores a 80\% compreendem toda a faixa litorânea e as regiões de Rio Grande, Pelotas, Triunfo, Campo Bom, Caxias do Sul, Bom Jesus, Cambará do Sul e Torres. No inverno, observa-se uma homogeneidade da umidade, com uma amplitude de apenas 5\%, variando entre 79\% a 84\%. Esses valores vão ao encontro do que Sartori (2003, p. 42) afirma que "a umidade relativa varia entre 70\% e 85\%, sendo, evidentemente, menor no verão e maior no inverno".

A umidade relativa do ar pode afetar o desenvolvimento da nogueira pecã, sobretudo das espécies mais sensíveis ao ataque de patógenos, especialmente os fúngicos que se propagam em função de elevada umidade relativa do ar, tais como o Cladosporium caryigenum e o Colletotrichum gloeosporioides. De acordo com Brison (1976), a umidade relativa do ar superior a 80\% dificulta a liberação do pólen das flores masculinas, resultando em menor fecundação e aumentando as chances de ocorrência de enfermidades fúngicas que atacam as folhagens. A variação histórica anual da umidade relativa do ar, a mediana, o desvio-padrão e os percentis podem ser verificados na Tabela 3.

\section{Tabela 3 - Umidade relativa do ar: média histórica anual, mediana, desvio padrão $(S)$ e percentis P5, P10, P90 e P95 no Rio Grande do Sul - 1998-2013}

\begin{tabular}{|c|c|c|c|c|c|c|c|}
\hline \multicolumn{8}{|c|}{ umidade relativa do ar $(\%)$} \\
\hline ano & média & mediana & $S(\%)$ & P5 & P10 & P90 & P95 \\
\hline 1998 & 80 & 81 & 3,9 & 73 & 75 & 84 & 85 \\
\hline 1999 & 75 & 75 & 6,8 & 66 & 68 & 83 & 85 \\
\hline 2000 & 78 & 78 & 4,8 & 70 & 74 & 83 & 83 \\
\hline 2002 & 80 & 79 & 2,8 & 76 & 77 & 84 & 85 \\
\hline 2003 & 78 & 79 & 3,1 & 73 & 74 & 81 & 83 \\
\hline 2004 & 77 & 76 & 3,8 & 71 & 72 & 82 & 83 \\
\hline 2005 & 77 & 76 & 3,7 & 72 & 72 & 83 & 84 \\
\hline 2006 & 77 & 76 & 4,2 & 72 & 72 & 83 & 84 \\
\hline 2007 & 78 & 78 & 3,4 & 74 & 74 & 83 & 84 \\
\hline 2008 & 77 & 77 & 4,1 & 71 & 72 & 81 & 85 \\
\hline 2009 & 79 & 79 & 3,6 & 73 & 73 & 82 & 85 \\
\hline 2010 & 78 & 78 & 4,1 & 72 & 73 & 83 & 86 \\
\hline 2011 & 77 & 77 & 4,2 & 70 & 71 & 82 & 82 \\
\hline 2012 & 74 & 74 & 4,2 & 67 & 69 & 80 & 81 \\
\hline 2013 & 77 & 77 & 4,4 & 72 & 73 & 82 & 84 \\
\hline
\end{tabular}

fonte: Inmet (2015). 
Quanto à média histórica anual da umidade relativa do ar, verificou-se que, dos 15 anos de análise, seis apresentaram a média histórica de 77\%: 2004, 2005, 2006, 2008, 2011 e 2013. O ano de 2012 apresentou a menor média histórica, 74\%. Os anos de 1998 e 2002, também os mais chuvosos, apresentaram a maior média, ou seja, $80 \%$. Nove dos 15 anos apresentaram mediana igual à média: 1999, 2000 e de 2007 a 2013. O desvio-padrão indica uma pequena dispersão dos dados em relação à média. $\bigcirc$ menor desvio-padrão foi em 2002 (2,8\%) e o maior, em 1999 (6,8\%).

Os percentis confirmam a variação da umidade. O menor valor do P5 foi em 1999 (66\%), enquanto seu P95 foi de 85\%. O maior valor do P5 foi em 2002, com 76\%, e o P95 nesse mesmo ano foi de $85 \%$. $\bigcirc$ ano de 2010 apresentou o maior valor do P95 (86\%), e o de 2012, o menor (81\%). Esses dados indicam a variação entre os menores e os maiores valores registrados, demonstrando que é preciso cautela ao se usarem apenas dados referentes à média.

A representação das horas de frio, com temperaturas inferiores a $7,2^{\circ} \mathrm{C}$, no período de maio a setembro, pode ser verificada na Figura 7. $\bigcirc$ mapa foi obtido pela digitalização do mapa original, elaborado por Herter et al. (2002). Como se pode observar, o estado apresenta uma variação significativa no número de horas de frio, um requisito importante para o desenvolvimento da nogueira pecã e também de outras frutíferas de clima temperado, que necessitam de um período de dormência ou repouso, condicionado pelas condições climáticas, que atuam como reguladoras de crescimento (Sentelhas; Angelocci, 2009).

Os menores acúmulos de horas de frio, entre 75 e 150 horas, são encontrados na porção noroeste do estado e, somando-se a ela, tem-se a faixa com valores entre $150 \mathrm{~h}$ a 200 horas, ambas no Vale do Rio Uruguai, na fronteira com a Argentina. Essas duas faixas compreendem as regiões de Uruguaiana, São Luiz Gonzaga e Iraí, no norte do estado. A região de 200 a 350 horas de frio, que envolve parte da porção noroeste, seguindo pela Depressão Central até parte da Planície Litorânea, está em locais com altitude até $500 \mathrm{~m}$ e compreende as regiões de Ibirubá, Santa Maria, Teutônia, Triunfo, Porto Alegre, Campo Bom, Torres, Pelotas e Rio Grande.

A região que compreende 350 a 500 horas de frio está em porções com altitudes entre 500 e 800 m, a nordeste do estado, compreendendo Passo Fundo e Bento Gonçalves. E ao sul, na Campanha e na Serra do Sudeste, em altitudes entre 200 e 500 m, compreendendo ainda a fronteira com o Uruguai, nas regiões de Santana do Livramento, Bagé, Encruzilhada do Sul e Santa Vitória do Palmar, onde as baixas temperaturas se devem muito mais à influência da latitude do que da altitude. As horas de frio superiores a 500 ocorrem nas regiões de maior altitude (superiores a 800 m), especialmente na Serra Gaúcha e na Serra do Nordeste, abrangendo Lagoa Vermelha, Bom Jesus, Caxias do Sul e Cambará do Sul. 
MAPA DE HORAS DE FRIO NO RIO GRANDE DO SUL

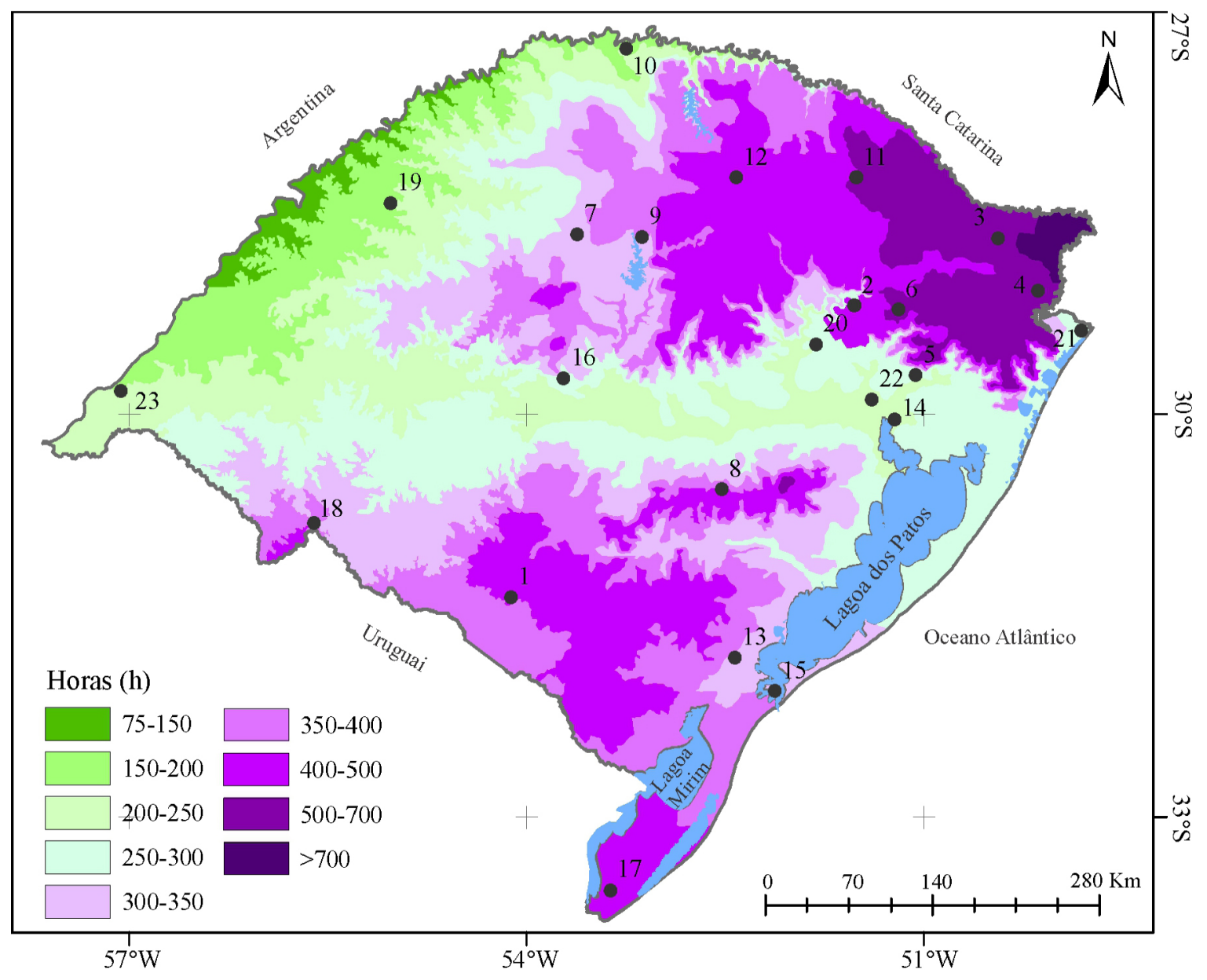

\section{Legenda}

\section{$\square$ Corpos d'água}

— Limite estadual

- Estações meteorológicas

1 - Bagé

2 - Bento Gonçalvez

3 - Bom Jesus

4 - Cambará do Sul

5 - Campo Bom

6 - Caxias do Sul

7 - Cruz Alta

8 - Encruzilhada do Sul
9 - Ibirubá

10 - Iraí

11 - Lagoa Vermelha

12 - Passo Fundo

13 - Pelotas

14 - Porto Alegre

15 - Rio Grande

16 - Santa Maria

17 - Santa Vitória do Palmar

18 - Santana do Livramento

19 - São Luiz Gonzaga

20 - Teutônia
21 - Torres

22 - Triunfo

23 - Uruguaiana

Base Cartográfica - Malha Digital Estadual do IBGE

Fonte dos dados - Mapa de horas de frio

(Herter, et al. 2002)

Sistema de Coordenadas

Geográficas

Datum SIRGAS 2000

As significativas variações do acúmulo de horas de frio no estado condicionam o cultivo da nogueira pecã, ainda que diferentes variedades de espécie venham sendo desenvolvidas e possam ser adaptadas a essas condições climáticas. A maioria dos autores que estuda esse cultivo (Raseira, 1990; Lemus, 2004; Grageda et al., 2013) destaca que a nogueira pecã demanda 
o acúmulo de mais de 400 horas de frio no período de dormência. No entanto, outros autores afirmam que a nogueira pode ser cultivada em regiões entre 250 e 550 horas (Madero; Frusso; Bruno, 2012) e mesmo entre 50 e 600 horas de frio (Ojeda-Barrios et al., 2009).

\section{Considerações finais}

Com base na análise realizada, constatou-se que a maioria dos requisitos climáticos para o desenvolvimento da nogueira pecã no estado foram atendidos, potencializando seu cultivo, exceto pelas horas de frio em algumas regiões. No verão, a temperatura média do ar variou entre $17^{\circ} \mathrm{C}$ e $27^{\circ} \mathrm{C}$, atendendo aos requisitos exigidos pela nogueira para desenvolver as nozes. A precipitação pluviométrica apresentou média anual de $1.651 \mathrm{~mm}$ com, variações significativas entre a região norte, com totais em torno de $2.000 \mathrm{~mm}$, e a região sul, com médias de $1.200 \mathrm{~mm}$ anuais, satisfazendo o requisito hídrico anual.

A umidade relativa do ar anual variou de $73 \%$ a $84 \%$, com descolamento no sentido noroeste-sudeste. Essa variável pode ser considerada adequada ao cultivo, mas deve-se atentar às regiões com valores superiores a 81\%, na faixa litorânea. Quanto às horas de frio, a distribuição no estado variou de 75 a mais de 700 horas. Esse requisito depende da variedade, que pode precisar de mais ou menos horas com temperatura abaixo de $7^{\circ} \mathrm{C}$, porém evidencia-se que a maior parte do território o atende, especialmente na Serra do Sudeste, na Campanha, em parte do Planalto, na Serra Gaúcha e na Serra do Nordeste.

\section{Referências}

ÁVILA, J. A. Importancia del reposo invernal y uso de compensadores de frío en nogal pecanero. In: DÍA DEL NOGALERO, 10., 2006, Chihuahua. Anais... Chihuahua, México, 2006.

BRISON, R. F. Cultivo del nogal pecanero. México: Conafrut. 1976.

$\mathrm{CABO}, \mathrm{A}$. N. P. El cultivo en el mundo e en Argentina. Informe Frutihorticola, Argentina, p. 14-15, 2006.

CPTEC. Centro de Previsão de Tempo e Estudos Climáticos. El Niño e La Niña. São Paulo: INPE, 2017. Disponível em: <http://enos.cptec.inpe.br/>. Acesso em: 14 ago. 2017.

DUARTE, V.; ORTIZ, E. R. N. Podridão de Phytophthora da amêndoa e casca da nogueira pecan. In: LUZ, E. D. M. N. et al. Doenças causadas por Phytophthora no Brasil. Campinas: Rural, 2001. p. 493-508.

EMATER-RS/ASCAR. Cultura da noz pecã em 2014 no Rio Grande do Sul: área total, produção e número de produtores. Porto Alegre: Emater-RS/Ascar, 2014.

FEIO, M. Clima e agricultura. Lisboa: Ministério da Agricultura, Pescas e Alimentação. 1991.

FRONZA, D.; HAMANN, J. J. Técnicas para o cultivo da nogueira-pecã. Santa Maria: Colégio Politécnico, 2016. 
FRONZA, D.; POLETTO, T.; HAMANN, J. J. O cultivo da nogueira-pecã. Santa Maria: Colégio Politécnico, 2013.

GRAGEDA, J. G. et al. El clima y la producción de nogal pecanero. In: SIMPOSIO INTERNACIONAL DE NOGAL PECANEIRO, 14., 2013, México. Anais... México: Instituto Nacional de Investigaciones Forestales, Agrícolas y Pecuarias, 2013. p. 55-66.

HEEREMA, R.; GOLDBERG, N.; THOMAS, S. Diseases and other disorders of pecan in New Mexico, Guide H-657, NM State University, p. 1-12, nov. 2010.

HERTER, F. G. et al. Zoneamento agroclimático do pessegueiro e da nectarina para o Rio Grande do Sul. Documentos - 91. Pelotas: Embrapa Clima Temperado, 2002.

IBGE. Instituto Brasileiro de Geografia e Estatística. Malha digital municipal. Formato shapefile. Rio de Janeiro: IBGE, 2015. Disponível em: http://downloads.ibge.gov.br/downloads_geociencias.htm. Acesso em: 14 abr. 2015.

Censo demográfico 2010. Tabela 200. Rio de Janeiro: 2010. Disponível em: http:// www.sidra.ibge.gov.br/bda/tabela/protabl.asp? $\mathrm{c}=200 \varepsilon_{\mathrm{z}}=\mathrm{t} \mathcal{E}_{\mathrm{o}}=1 \mathcal{E} \mathrm{i}=\mathrm{P}$. Acesso em: 6 maio 2015.

INMET. Instituto nacional de Meteorologia. Dados meteorológicos: estações convencionais. Brasilia: 2015. Disponível em: <http://www.inmet.gov.br/portal/index. php? $r=e s t a c o e s / e s t a c o e s C o n v e n c i o n a i s>$. Acesso em: 4 abr. 2018.

LACERDA, M.; LORENZI, H. Frutas brasileiras e exóticas cultivadas: de consumo in natura. São Paulo: Nova Cultura, 2006.

LEMUS, G. El cultivo del pecano (Carya illinoinensis). Chile: Ministerio de Agricultura, 2004

MADERO, E. R. La nuez pecán. Idia XXI, Buenos Aires, v. 3, n. 5, p. 78-82, 2003.

; FRUSSO, E. A.; BRUNO, N. R. Desarrollo del cultivo de la nuez pecan en la Argentina. Buenos Aires: PreCan/Procadis/Inta/Ministerio de Agricultura, Ganadería Y Pesca, 2012.

MANASTER, J .The Pecan Tree. Austin: University of Texas Press, 1994.

MONTEIRO, A. et al. Attlas da saúde e da doença: vulnerabilidades climáticas e socioeconómicas. Porto, PT: Universidade do Porto, 2012. v. II.

MOTA; F. S.; ZAHLER, P. J. M. Clima, agricultura e pecuária no Rio Grande do Sul. Pelotas: Mundial, 1994.

OJEDA-BARRIOS, D. L. et al. Evolución de los sistemas de producción de nuez en México. Tecnociencia, Chihuahua, v. 3, n. 3, p. 115-120, set./dez. 2009.

OMM. World Climate Programme Data. Calculation of monthly and annual 30-years standard normals. WMO-TD - No 341. Washington: WMO, 1989.

PETERSON, J. K. Pecan: Carya illinoinensis (Wangenh.) K. Koch. Hardwoods: Silvics of North America, 1990. v. 2. 
RASEIRA, A. A cultura da nogueira pecã. Comunicado técnico. Pelotas: Embrapa, n. 63, p. 3, abr. 1990.

ROSSATO, M. S. Os climas do Rio Grande do Sul: variabilidade, tendências e tipologias. Tese (Doutorado em Geografia) - Instituto de Geociências, Universidade Federal do Rio Grande do Sul, Porto Alegre, 2011.

SARTORI, M. G. B. A dinâmica do clima do Rio Grande do Sul: indução empírica e conhecimento científico. Revista Terra Livre, São Paulo, v. 1, n. 20, p. 27-49, jan./jul. 2003. Clima e percepção. Tese (Doutorado em Geografia) - Faculdade de Filosofia, Letras e Ciências Humanas, Universidade de São Paulo, São Paulo, 2000.

A circulação atmosférica regional e os principais tipos de sucessão do tempo no inverno do Rio Grande do Sul, Brasil. Ciência e Natura, Santa Maria, v. 1, n. 15, p. 69-93, 1993.

SENTELHAS, P. C.; ANGELOCCI, L. R. Temperatura do ar como fator agronômico (anotações de aula). São Paulo: Esalq-USP, 2009. Disponível em: www.lce.esalq.usp.br/aulas/lce306/Aula10.pdf. Acesso em: 18 set. 2015.

SIERRA, E. M.; LÓPEZ, E. L.; PÉREZ, S. P. Agroclimatología del pecán (Carya illinoinensis) en la Argentina. In: LAVADO, R. S.; FRUSSO, E. A. (Org.). Producción de pecán en Argentina. Buenos Aires: 2007. p. 1-10.

SPARKS, D. A. Adaptability of Pecan as a Species. HortScience, Georgia, v. 40, n. 5, p. 1175.1189, 2005.

A Climatic Model for Pecan Production under Humid Conditions. Journal of the American Society Horticultural Science, Georgia, v. 121, n. 5, p. 908-914, 1996.

. A climatic approach to pecan scab control. Hort Technology, v. 5, n. 3, p. 225-230, 1995.

WEBER, E.; HASENACK, H.; FERREIRA, C. J. C. Adaptação do modelo digital de elevação do SRTM para o sistema de referência oficial brasileiro e recorte por unidade de federação. Porto Alegre: Centro de Ecologia-UFRGS, 2000. Disponível em: http://www.ecologia.ufrgs.br/labgeo. Acesso em: 14 abr. 2015. 